\title{
Quantitative selenium metabolism in normal New Zealand women
}

\author{
BY R. D. H. STEWART, NORA M. GRIFFITHS, \\ CHRISTINE D. THOMSON AND MARION F. ROBINSON \\ Department of Nutrition and Department of Medicine, University of Otago, Dunedin, \\ New Zealand
}

(Received 22 June 1976 - Accepted 4 August 1976)

I. Quantitative selenium metabolism has been studied in normal young New Zealand women by measuring total Se intake and urinary and faecal Se output, and by using values for absorption, excretion and turnover of ${ }^{75} \mathrm{Se}$ determined after administration of $\left[{ }^{75} \mathrm{Se}\right]$ selenomethionine or $\left[{ }^{75} \mathrm{Se}\right]$ selenite.

2. In a period of $14 \mathrm{~d}$ when a normal ad lib. diet was being consumed, mean dietary Se for four women was $24.2 \mu \mathrm{g} / \mathrm{d}$, mean urinary Se was $13.1 \mu \mathrm{g} / \mathrm{d}$ and mean faecal Se was $10.8 \mu \mathrm{g} / \mathrm{d}$; mean Se balance during this time was $+0.3 \mu \mathrm{g} / \mathrm{d}$.

3. Intestinal absorption of food Se was $0.76-0.83$ of intake (mean 0.79 ).

4. Whole-body Se was calculated in three different ways; $(a)$ using the specific activity of urinary Se and retained whole-body ${ }^{75} \mathrm{Se} ;(b)$ using plasma Se and the occupancy of ${ }^{75} \mathrm{Se}$ in whole-body and plasma; $(c)$ using absorbed food Se and the occupancy of absorbed ${ }^{75} \mathrm{Se}$ in whole-body.

5. Whole-body Se calculated from measurements obtained following the administration of [ $\left.{ }^{55} \mathrm{Se}\right]$ selenomethionine was 4.7-10.0 mg (mean 6.9) using method (a), 4. I-7.2 mg (mean 5.2) using method (b) and 4.3$8.9 \mathrm{mg}$ (mean 6.2) using method $(c)$.

6. Whole-body Se calculated from results obtained after giving [ ${ }^{75}$ Se]selenite was $2.7-3.4$ mg (mean 2.9) using method $(a), 2 \cdot 3-5.0 \mathrm{mg}$ (mean 3.5) using method $(b)$ and $2 \cdot 1-3 \cdot 0 \mathrm{mg}$ (mean $2 \cdot 6$ ) using method (c).

7. The results of this study indicate that the minimum dietary requirement of Se for the maintenance of normal human health is probably not more than $20 \mu \mathrm{g} / \mathrm{d}$.

Top soils in New Zealand have Se concentrations of $0 \cdot 1-4 \cdot 0 \mu \mathrm{g} / \mathrm{g}$ and in many regions, including most of the arable lands of the South Island, the soil Se concentration is less than $0.5 \mu \mathrm{g} / \mathrm{g}$ (Wells, 1967). In these latter areas there is, in the absence of Se dosing, a high incidence of Se-responsive disorders in farm livestock (Andrews, Hartley \& Grant, 1968). The possibility that Se-responsive disorders also occur in residents of these areas has been raised by reports of alleged benefit and relief from muscular complaints in such persons after self medication with sodium selenite (Hickey, I968). Certainly, Se levels in blood and urine of New Zealand residents are low compared with those reported for persons living in Europe or North America (Thomson, 1972; Griffiths, I973; Griffiths \& Thomson, 1974; Watkinson, 1974); accordingly New Zealanders are perhaps at a greater risk of ill health as a result of Se deficiency than persons living in many other parts of the world.

We have studied the utilization of ${ }^{75} \mathrm{Se}$ administered in various forms to rats (Thomson \& Stewart, I973; Thomson, Stewart \& Robinson, 1975; Thomson, Robinson, Stewart \& Robinson, 1975; Richold, Robinson \& Stewart, 1977) and have reported studies of ${ }^{75} \mathrm{Se}$ absorption, excretion and turnover in New Zealand women following the administration of tracer amounts of $\left[{ }^{75} \mathrm{Se}\right]$ sodium selenite or $\left[{ }^{75} \mathrm{Se}\right]$ selenomethionine (Thomson \& Stewart, I974; Griffiths, Stewart \& Robinson, I 976). In the present investigation we have documented the pattern of Se intake and excretion by women following an ad lib. diet and have attempted to assess utilization of food Se and to estimate whole-body Se in these same persons. 


\section{EXPERIMENTAL}

\section{Procedure}

The measurements for this study were made during the study of the metabolism of $\left[{ }^{75} \mathrm{Se}\right]$ selenomethionine in four women (Griffiths et al. 1976) and during the study of the metabolism of $\left[{ }^{75} \mathrm{Se}\right]$ selenite in young women (Thomson \& Stewart, 1974). The details of the timing and methods of collection of samples of blood, urine and faeces and of measurement of radioactivity in plasma, urine, faeces and whole-body and of stable Se in urine and faeces are given in these previous reports. Plasma Se was measured using the method previously described for whole blood Se (Griffiths \& Thomson, 1974).

The subjects for the study of $\left[{ }^{75} \mathrm{Se}\right]$ selenomethionine metabolism were four women, $\mathrm{G}, \mathrm{R}$, $\mathrm{C}$ and $\mathrm{T}$ aged $34,26,22$ and 23 years respectively and those for the study of [ $\left.{ }^{75} \mathrm{Se}\right]$ selenite metabolism undertaken in the previous year were three women, $G, R$ and $W$ aged 33, 25 and 20 years respectively. $G$ and $R$ participated in both studies. Informed consent was obtained from all subjects.

The subjects in the selenomethionine study each received $20 \mu \mathrm{Ci}{ }^{75} \mathrm{Se}$ which is estimated to deliver I30-I $68 \mathrm{mrad}$ whole-body radiation dose and $200 \mathrm{mrad}$ gonad dose (ICRP, I97I), and in the selenite study each received $10 \mu \mathrm{Ci}{ }^{75} \mathrm{Se}$ which would have delivered a proportionately smaller radiation dose because of the shorter biological half life of selenium given as selenite. These estimated radiation doses are within acceptable limits recommended for members of the general public by international agencies (ICRP, I966).

\section{Measurement of Se intake and output}

Throughout the first $\mathrm{I} 4 \mathrm{~d}$ of the selenomethionine study, all food and drink for each of the four subjects was prepared as identical duplicate servings, one of which was consumed. The other serving was pooled with all duplicate servings of food and drink consumed in each $24 \mathrm{~h}$ period for subsequent analysis of stable Se content, as previously described (Robinson, McKenzie, Thomson \& van Rij, 1973). Se was also measured in each $24 \mathrm{~h}$ collection of urine for these $14 \mathrm{~d}$ and individually in all faecal samples passed, beginning with the sample containing the brilliant blue marker given with the $\left.{ }^{75} \mathrm{Se}\right]$ selenomethionine dose on day $\mathrm{I}$ and finishing with the last sample passed before the appearance of the brilliant blue marker taken before breakfast on day I5 (Griffiths et al. 1976).

Urinary and faecal Se outputs were similarly determined for each subject in the selenite study, but there were no measures of Se intake.

\section{Measurement of ${ }^{75} \mathrm{Se}$ occupancy}

The occupancy of the ${ }^{75} \mathrm{Se}$ dose is defined as the mean duration of stay of the ${ }^{75} \mathrm{Se}$ dose in the compartment concerned (Orr \& Gillespie, I968). The occupancy in whole-body and in I 1 of plasma was calculated by determining the integral value for whole-body ${ }^{75} \mathrm{Se}$ (measured as dose administered less cumulative urinary and faecal loss) or plasma ${ }^{75} \mathrm{Se}$ (fraction of dose/1). Whole-body and plasma ${ }^{75} \mathrm{Se}$ curves could both be resolved into three exponential components (Thomson \& Stewart, 1974; Griffiths et al. 1976). Thus:

$$
y=\mathrm{A} e^{-\alpha t}+\mathrm{B} e^{-\beta t}+\mathrm{C} e^{-\gamma t},
$$

where $y$ is whole-body or plasma ${ }^{75} \mathrm{Se}, t$ is time (d) from the administration of the ${ }^{75} \mathrm{Se}$ dose and $\mathrm{A}, \mathrm{B}, \mathrm{C}, \alpha, \beta$ and $\gamma$ are derived constants. Accordingly the occupancy $(\theta)$ of the ${ }^{75} \mathrm{Se}$ dose is given by:

$$
\theta=\int_{0}^{\infty} y \cdot \mathrm{d} t=\frac{\mathrm{A}}{\alpha}+\frac{\mathrm{B}}{\beta}+\frac{\mathrm{C}}{\gamma} .
$$


Table I. Selenium intake and excretion for $14 d$ by four New Zealand women eating a normal diet

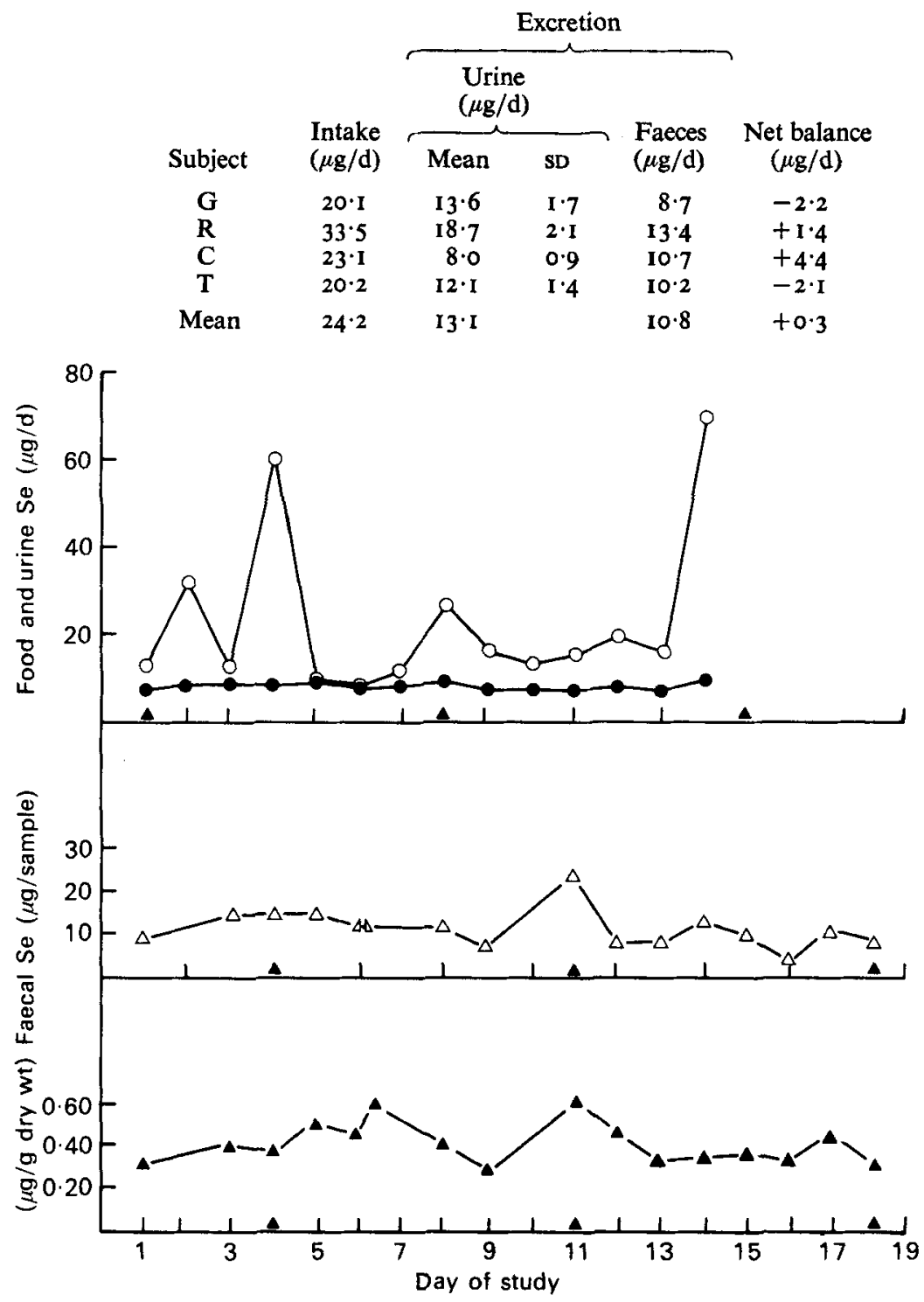

Fig. I. Food $(O)$, urine $(\bullet)$ and faecal $(\triangle, \Delta)$ Se for subject $C$ while following an ad lib. diet for $14 \mathrm{~d}$. The time of administration of the brilliant blue faecal marker with the dose on day $I$ and before breakfast on days 8 and I 5, and of its appearance in the stool, is shown by $\Delta$ on the ordinates. For details of experimental methods see p. 46.

\section{RESULTS}

Se intake and output

Mean intake of Se by the subjects while following a normal ad lib. diet for I $4 \mathrm{~d}$ was $24 \cdot 2 \mu \mathrm{g} / \mathrm{d}$ (Table 1 ). Mean urinary excretion in the same period was $13.1 \mu \mathrm{g} / \mathrm{d}$, and mean faecal loss was $10.8 \mu \mathrm{g} / \mathrm{d}$. Net mean Se balance for these subjects in the study period was thus 
Table 2. Intestinal absorption of food Se by New Zealand women eating a normal diet

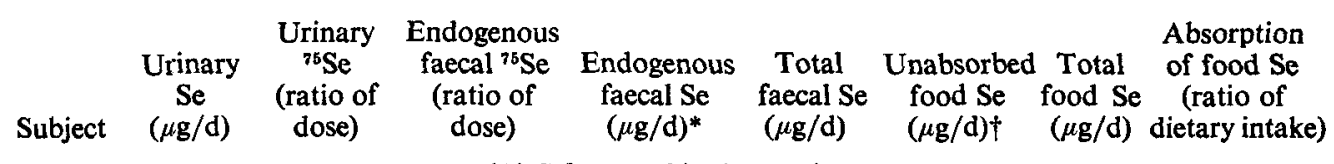

(A) Selenomethionine study

$\begin{array}{ccccccccc}\text { G } & 13.6 & 0.479 & 0.165 & 4.7 & 8.7 & 4.0 & 20.1 & 0.80 \\ \text { R } & 18.7 & 0.366 & 0.123 & 6.3 & 13.4 & 7.1 & 33.5 & 0.79 \\ \text { C } & 8.0 & 0.324 & 0.247 & 6.1 & 10.7 & 4.6 & 23.1 & 0.80 \\ \text { T } & 12.1 & 0.315 & 0.136 & 5.3 & 10.2 & 4.9 & 20.2 & 0.76 \\ \text { Mean } & 13.1 & - & - & 5.6 & 10.8 & 5.2 & 24.2 & 0.79\end{array}$

$\begin{array}{crcccrccc}\mathbf{G} & 18.1 & 0.364 & 0.102 & 5.1 & 9.7 & 4.6 & 27.8 \ddagger & 0.83 \\ \mathbf{R} & 12.7 & 0.199 & 0.077 & 4.9 & 10.2 & 5.3 & 22.9 \ddagger & 0.77 \\ W & 8.5 & 0.214 & 0.161 & 6.4 & 9.8 & 3.4 & 18.3 \ddagger & 0.81 \\ \text { Mean } & 13.1 & - & - & 5.5 & 9.9 & 4.4 & 23.0 & 0.80\end{array}$

* Calculated as described on p. 49.

$\dagger$ Calculated as the difference between endogenous faecal Se and total faecal Se.

$\ddagger$ Calculated as the sum of urinary and faecal Se.

$+0.3 \mu \mathrm{g} / \mathrm{d}$. Analysis of the individual diets revealed a mean energy intake of $9.3,6.4,7 \cdot 7$ and $8.6 \mathrm{MJ} / \mathrm{d}$ for subjects $\mathrm{G}, \mathrm{R}, \mathrm{C}$ and $\mathrm{T}$ respectively. Protein contributed $0.12-0.14$ of the energy of the four diets, fat contributed $0.37-0.44$ and carbohydrate $0.44-0.5 \mathrm{I}$ (H. Poh, private communication).

A similar pattern of day-to-day variation of food and urinary Se and of sample-to-sample variation of faecal Se was observed in all subjects. The individual values for Subject $\mathrm{C}$ are shown in Fig. I. There was considerable day-to-day variation of food Se in all subjects, the values ranging from 9-42 $\mu \mathrm{g} / \mathrm{d}$ for subject $\mathrm{G}$, from $10-102 \mu \mathrm{g} / \mathrm{d}$ for $\mathrm{R}$, from $8-70 \mu \mathrm{g} / \mathrm{d}$ for C and $5-35 \mu \mathrm{g} / \mathrm{d}$ for $\mathrm{T}$. Inspection of the records of meal content showed that fish, liver, kidney or eggs, foods known to have a high Se content (Sakurai \& Tsuchiya, 1975; Robinson, I976), were included on all days except one in which Se intake was more than $30 \mu \mathrm{g}$.

Urine $\mathrm{Se}$, on the other hand, showed little day-to-day variation, so that on 53 of 56 subject-days $24 \mathrm{~h}$ urinary Se was within the range $\pm 3 \mu \mathrm{g}$ from the mean value for the individual subject. In the $3 \mathrm{I}-42$ weeks immediately after the $\mathrm{I} 4 \mathrm{~d}$ study each subject collected a further eighteen-twenty $24 \mathrm{~h}$ urine samples which contained (mean $\pm \mathrm{SD}$ ) I3.0 $\pm \mathrm{I} \cdot 6, \mathrm{I} \cdot \mathrm{I} \pm$ $3 \cdot 7,8 \cdot 4 \pm \mathrm{I} \cdot \mathrm{I}$ and $\mathrm{I} 2 \cdot \mathrm{I} \pm \mathrm{I} \cdot 5 \mu \mathrm{g} \mathrm{Se} / \mathrm{d}$ respectively for subjects $\mathrm{G}, \mathrm{R}, \mathrm{C}$ and $\mathrm{T}$, values closely similar to those observed in the initial I $4 \mathrm{~d}$ study. Despite the small daily variation of urine Se there was a correlation between food Se and urine Se in the I $4 \mathrm{~d}$ study for subjects R ( $r$ $+0.8 \mathrm{r} ; P<0.0 \mathrm{I})$ and $\mathrm{C}(r+0.64 ; P<0.01)$. There was no significant correlation between these variables for subjects $\mathrm{G}(r+0.42)$ or $\mathrm{T}(r+0.37)$.

The use of the brilliant blue marker gives an estimate of intestinal transit time and thus allows a comparison of faecal Se content with the corresponding food intake. For subject C, it can be seen from Fig. I that the faecal samples with the highest Se concentrations probably corresponded with the higher Se intake on days 2,4 and 8 respectively. The relationship between food and faecal Se for the other subjects was less clear.

Urinary Se (mean \pm SD) in the selenite study (Thomson \& Stewart, I974) was $I 8 \cdot I \pm 0 \cdot 8$, $12 \cdot 7 \pm \mathrm{I} \cdot 7$ and $8 \cdot 5 \pm \mathrm{I} \cdot 0 \mu \mathrm{g} / \mathrm{d}$ and mean faecal Se was $9.7,10 \cdot 2$ and $9.8 \mu \mathrm{g} / \mathrm{d}$ for subjects $G, R$ and $W$ respectively. 
Table 3. Whole-body Se ( $m g$ ) calculated from whole-body ${ }^{75}$ Se and specific activity of urine Se $(\operatorname{method} a)^{*}$

(A) Selenomethionine study

\begin{tabular}{|c|c|c|c|c|c|c|c|c|c|c|c|c|c|}
\hline Week & 12 & 14 & $16-17$ & $18-19$ & $20-21$ & $22-23$ & $24^{-25}$ & $26-27$ & 29 & $3^{31-32}$ & 33 & $37-39$ & Mean \\
\hline \multicolumn{14}{|c|}{ Subject } \\
\hline G & 50 & $4 \cdot 7$ & $5 \cdot 2$ & $5 \cdot 6$ & $5 \cdot 3$ & $6 \cdot 5$ & $4 \cdot 8$ & 5.4 & $5 \cdot 1$ & $6 \cdot 7$ & 5.0 & $5 \cdot 2$ & $5 \cdot 4$ \\
\hline $\mathbf{R}$ & $12 \cdot I$ & $6 \cdot 7$ & $10 \cdot 3$ & II $\cdot 9$ & $7 \cdot 9$ & $8 \cdot 9$ & $9 \cdot 8$ & II 4 & - & 10 & - & - & 10. \\
\hline C & $4 \cdot 5$ & $4 \cdot 2$ & $5 \cdot 0$ & 49 & $4 \cdot 8$ & $4 \cdot 4$ & $6 \cdot 1$ & 4. & $\rightarrow$ & 5 & $\overline{5}$ & 3.5 & 47 \\
\hline $\mathbf{T}$ & 8.0 & $6 \cdot 6$ & $8 \cdot I$ & 6.8 & 7.9 & 7.8 & 7.0 & $7 \cdot 0$ & $8 \cdot 1$ & $8 \cdot 4$ & 6.4 & & \\
\hline
\end{tabular}

(B) Selenite study

\begin{tabular}{|c|c|c|c|c|c|c|c|c|c|c|c|c|c|}
\hline Week ... & 5 & 6 & 7 & 8 & 9 & 10 & I I & $12-13$ & 14 & - & - & - & Mean \\
\hline G & 3.0 & $2 \cdot 9$ & $3 \cdot 1$ & 3.4 & $3 \cdot 2$ & 3.8 & $3 \cdot 3$ & $3 \cdot 3$ & 5.0 & - & - & - & 34 \\
\hline $\mathbf{R}$ & $2 \cdot 3$ & $2 \cdot 0$ & $2 \cdot 0$ & $4 \cdot 2$ & 3.2 & $2 \cdot 2$ & $3 \cdot 2$ & - & - & - & - & - & $2 \cdot 7$ \\
\hline W & $2 \cdot 3$ & $2 \cdot 4$ & 2.8 & $2 \cdot 6$ & - & - & - & 3.0 & 2.8 & - & - & - & 2.7 \\
\hline
\end{tabular}

\section{Intestinal absorption of food Se}

Intestinal absorption of food Se by the four subjects given $\left[{ }^{75} \mathrm{Se}\right]$ selenomethionine was calculated by estimating endogenous faecal Se from the relationship:

$$
\frac{\text { endogenous faecal Se }}{\text { endogenous faecal }{ }^{75} \mathrm{Se}}=\frac{\text { urinary } \mathrm{Se}}{\text { urinary }{ }^{75} \mathrm{Se}} \text {. }
$$

For this purpose, the cumulative urinary loss of ${ }^{75} \mathrm{Se}$ during the whole period of observation after the administration of the $\left.{ }^{75} \mathrm{Se}\right]$ selenomethionine dose (33-44 weeks) was used together with the cumulative faecal ${ }^{75} \mathrm{Se}$ in the same period, less unabsorbed radioactivity. The results used for the calculations are presented in Table 2. Intestinal absorption of food Se was $0.80,0.79,0.80$ and 0.76 for subjects, G, R, C and T respectively, the mean value being 0.79 .

A similar estimate of intestinal absorption of food Se was made for the three subjects given $\left[{ }^{75}\right.$ Se]selenite. However, in this study, food Se was not measured directly but has been estimated as equal to the sum of mean urinary and mean total faecal Se during the initial period of observation in these three subjects. Estimated intestinal absorption of food Se in this study was $0.83,0.77$ and 0.81 for subjects $G, R$ and $W$ respectively, the mean value being 0.80 (Table 2).

\section{Whole-body Se}

Whole-body Se has been estimated using three methods. The first method (a) employs the postulated relationship:

$$
\frac{\text { whole-body Se }}{\text { whole-body }{ }^{75} \mathrm{Se}}=\frac{\text { urinary Se }}{\text { urinary }{ }^{75} \mathrm{Se}} \text {. }
$$

For this calculation, the results used were those obtained after week 12 for the four subjects given $\left.{ }^{75} \mathrm{Se}\right]$ selenomethionine and after week 5 for the three subjects given $\left.{ }^{75} \mathrm{Se}\right]$ selenite. Thus $9-12$ coincident values for urinary Se, urinary ${ }^{75} \mathrm{Se}$ and whole-body retained ${ }^{75} \mathrm{Se}$ (dose administered less cumulative faecal and urinary losses) at approximately fortnightly intervals were available for each subject in the selenomethionine study, and 6-9 values at approximately weekly intervals for each subject in the selenite study (Table 3). Whole-body Se calculated in this manner using the selenomethionine results was $5.4,10.0,4.7$ and $7.5 \mathrm{mg}$ 
Table 4. Whole-body Se calculated from plasma Se and occupancy of ${ }^{75}$ Se in whole body and in plasma (method $b)^{*}$

\begin{tabular}{|c|c|c|c|c|}
\hline Subject & $\begin{array}{c}{ }^{75} \mathrm{Se} \text { occupancy } \\
\text { in plasma } \\
\text { (d/l) }\end{array}$ & $\begin{array}{c}\text { Plasma } \\
\text { Se } \\
(\mu \mathrm{g} / 1)\end{array}$ & $\begin{array}{c}{ }^{75} \text { Se occupancy } \\
\text { in whole-body } \\
\text { (d) }\end{array}$ & $\begin{array}{l}\text { Whole-bod } \\
\text { Se } \\
\text { (mg) }\end{array}$ \\
\hline \multicolumn{5}{|c|}{ (A) Selenomethionine study } \\
\hline $\begin{array}{l}\mathbf{G} \\
\mathbf{R} \\
\mathbf{C} \\
\mathbf{T}\end{array}$ & $\begin{array}{l}2 \cdot 9 \\
3 \cdot 4 \\
3 \cdot 5 \\
4 \cdot 1\end{array}$ & $\begin{array}{l}48 \\
76 \\
49 \\
58\end{array}$ & $\begin{array}{l}258 \\
323 \\
294 \\
374\end{array}$ & $\begin{array}{l}4 \cdot 3 \\
7 \cdot 2 \\
4 \cdot 1 \\
5 \cdot 3\end{array}$ \\
\hline Mean & 3.5 & 58 & 312 & $5 \cdot 2$ \\
\hline \multicolumn{5}{|c|}{ (B) Selenite study } \\
\hline $\begin{array}{l}\mathbf{G} \\
\mathbf{R} \\
\mathbf{W}\end{array}$ & $\begin{array}{l}2 \cdot 7 \\
1 \cdot 2 \\
1 \cdot 4\end{array}$ & $\begin{array}{l}69+ \\
73 \dagger \\
63 \dagger\end{array}$ & $\begin{array}{r}90 \\
52 \\
112\end{array}$ & $\begin{array}{l}2 \cdot 3 \\
3 \cdot 2 \\
5 \cdot 0\end{array}$ \\
\hline Mean & $1 \cdot 8$ & $68 \dagger$ & 85 & $3 \cdot 5$ \\
\hline
\end{tabular}

for subjects $\mathrm{G}, \mathrm{R}, \mathrm{C}$ and $\mathrm{T}$ respectively, and using the selenite results $3.4,2 \cdot 7$ and $2 \cdot 7 \mathrm{mg}$ for subjects $G, R$ and $W$ respectively. In no subject was there a significant correlation between the individual calculated values for whole-body Se obtained by this method and the time expired from the administration of the ${ }^{75} \mathrm{Se}$ dose.

Whole-body Se was also estimated from plasma Se and the occupancy of ${ }^{75} \mathrm{Se}$ in whole-body and plasma (method $b$ ), according to the postulated relationship (Orr \& Gillespie, 1968; Riviere, Comar, Kellershohn, Orr, Gillespie \& Lenihan, 1969):

$$
\frac{\text { whole-body Se }}{\text { whole-body occupancy of }{ }^{75} \mathrm{Se}}=\frac{\text { plasma Se }}{\text { plasma occupancy of }{ }^{75} \mathrm{Se}} .
$$

Whole-body Se determined in this way, using values obtained following the administration of [ $\left.{ }^{75} \mathrm{Se}\right]$ selenomethionine, was $4 \cdot 3,7 \cdot 2,4 \cdot 1$ and $5 \cdot 3 \mathrm{mg}$ for subjects $\mathrm{G}, \mathrm{R}, \mathrm{C}$ and $\mathrm{T}$, the mean value being $5.2 \mathrm{mg}$ (Table 4). The respective values obtained for the three subjects in the selenite study were $2.3,3.2$ and $5.0 \mathrm{mg}$ for $\mathrm{G}, \mathrm{R}$ and $\mathrm{W}$, the mean being $3.5 \mathrm{mg}$. For these latter calculations, as no plasma Se measurements had been made, whole blood Se values were used.

For method $(c)$, whole-body Se was derived from the whole-body occupancy of absorbed ${ }^{75} \mathrm{Se}$ and absorbed food Se using the postulated relationship (Orr \& Gillespie, 1968):

whole-body $\mathrm{Se}=$ whole-body occupancy of absorbed ${ }^{75} \mathrm{Se} \times$ absorbed food Se.

Whole-body occupancy of absorbed ${ }^{75} \mathrm{Se}$ was determined by dividing the value obtained for the whole-body occupancy of the ${ }^{75} \mathrm{Se}$ dose by the individual value for the intestinal absorption of the ${ }^{75}$ Se tracer (Thomson \& Stewart, 1974; Griffiths et al. 1976) and values for absorbed food Se were calculated as the difference between total food Se and unabsorbed food Se, using the results presented in Table 2. The values for whole-body Se obtained using method (c) and the results of the selenomethionine study were $4 \cdot 3,8 \cdot 9,5.7$ and $5.9 \mathrm{mg}$ for $\mathrm{G}, \mathrm{R}, \mathrm{C}$ and $\mathrm{T}$ respectively, the mean being $6.2 \mathrm{mg}$ (Table 5). The corresponding values for the subjects given $\left[{ }^{75} \mathrm{Se}\right]$ selenite were respectively $3 \cdot 0,2 \cdot 1$ and $2.6 \mathrm{mg}$ for $\mathrm{G}, \mathrm{R}$ and $\mathrm{W}$, the mean being $2.6 \mathrm{mg}$. 
Table 5. Whole-body Se calculated from whole-body occupancy of ${ }^{75} \mathrm{Se}$ and absorbed food Se $(\text { method } c)^{*}$

$\begin{array}{cccc}\text { Absorbed } & \text { i5Se occupancy } \\ \text { in whole-body } & \begin{array}{c}\text { Absorbed } \\ \text { food Se } \\ (\mu \mathrm{g} / \mathrm{d})\end{array} & \begin{array}{c}\text { Whole-body } \\ (\mathrm{mg})\end{array} \\ \text { Subject } & \text { (d) } & (\mu \mathrm{d}) & \end{array}$

(A) Selenomethionine study

$\begin{array}{cccc}G & 266 & 16 \cdot I & 4 \cdot 3 \\ R & 336 & 26 \cdot 4 & 8 \cdot 9 \\ C & 307 & 18 \cdot 5 & 5 \cdot 7 \\ T & 386 & 15 \cdot 3 & 5 \cdot 9 \\ \text { Mean } & 324 & 19 \cdot 1 & 6 \cdot 2\end{array}$

(B) Selenite study

$\begin{array}{cccc}\mathbf{G} & 129 & 23.2 & 3.0 \\ \mathbf{R} & 118 & 17.6 & 2 \cdot \mathrm{I} \\ \mathbf{W} & 175 & 14.9 & 2.6 \\ \text { Mean } & \text { I4I } & 18.6 & 2.6 \\ & \text { * For experimental details see p. 50. }\end{array}$

DISCUSSION

Se intake and output

Very little is known concerning the normal Se intake of persons living in different parts of the world. Schroeder, Frost \& Balassa (I970), using food tables, estimated an intake of $60-150 \mu \mathrm{g} / \mathrm{d}$ for persons living in the United States, and Sakurai \& Tsuchiya (1975) similarly calculated a mean intake of $100 \mu \mathrm{g} / \mathrm{d}$ for adult Japanese. Thompson, Erdody \& Smith (1975), who analysed four standard composite Canadian diets, found Se contents of I I $3-220 \mu \mathrm{g} / \mathrm{d}$, and from food tables calculated an average intake of $197 \mu \mathrm{g} / \mathrm{d}$ for all residents of that country.

Much lower values have been found for normal New Zealand diets. Griffiths (I973) found Se intakes varying from $6-70 \mu \mathrm{g} / \mathrm{d}$ for thirteen young women following an unrestricted diet for 3-2I d and the mean intake of the subjects in the present study was $24 \mu \mathrm{g} / \mathrm{d}$. Thus residents in Dunedin, and also probably in other parts of New Zealand, have a Se intake which is lower by a factor of at least 3-4 than that estimated for residents in North America or Japan.

The very considerable day-to-day variation of Se intake exhibited by persons following an ad lib. diet is a noteworthy observation. It suggests that those New Zealanders whose diet contains little fish, liver, kidney or eggs, whether because of poverty, illness, belief or habit, would individually have a mean Se intake of less than $20 \mu \mathrm{g} / \mathrm{d}$, and therefore could be at risk of ill-health as a consequence of Se deficiency.

Despite the considerable daily variations of intake, urinary Se remained virtually constant with only a small direct effect of recent intake upon urine output. Similarly faecal Se appears to have been only marginally affected by recent intake, although this is less easily assessed because of the smoothing effect of intestinal transit and irregularity of bowel function. These findings would suggest that, at least for persons with a low Se intake, there is a high utilization of food Se, the greater proportion of which appears to be incorporated into the longterm body pool, and that urine Se mostly reflects body 'stores' of Se rather than recent intake.

In the present study there was an apparent mean Se balance of $+0 \cdot 3 \mu \mathrm{g} / \mathrm{d}$. Similar results were obtained by Robinson et al. (1973) in a metabolic balance study of two subjects following a constant diet containing $24-26 \mu \mathrm{g} \mathrm{Se} / \mathrm{d}$ for $18 \mathrm{~d}$. Both these studies were undertaken in 
Dunedin and the results may not be applicable to persons with higher Se intakes. Moreover, the duration of these studies was short so that a true balance may not have been established. Nevertheless, the similarity of the results for all subjects in the two independent studies and the condition that subjects for the present investigation were to follow their normal ad lib. food intake, makes it probable that the apparent external balance of Se in these young women is a valid observation. If this is accepted, there can have been little loss of Se by routes other than urine and faeces in our subjects. These findings are at variance with the undocumented suggestion that residents of the United States lose about half their daily intake of Se through the skin or in expired air (Schroeder et al. 1970).

\section{Intestinal absorption of food Se}

Our previously reported measurements showed that the intestinal absorption of $\left[{ }^{75} \mathrm{Se}\right]$ selenomethionine was much more complete than that of $\left[{ }^{75} \mathrm{Se}\right]$ selenite (Thomson \& Stewart, I974; Griffiths et al. 1976). In the absence of any knowledge of the chemical form of digested food $\mathrm{Se}$, it was not possible to use these results to predict the efficiency of absorption of Se from a normal mixed diet, but the method described in this paper does appear to provide a reasonable alternative. This method depends upon the assumption that absorbed tracer ${ }^{75} \mathrm{Se}$ is partitioned for excretion between urine and faeces in the same proportions as is absorbed food Se. This assumption may be questioned in view of the difference we have shown between the metabolism of $\left.{ }^{75} \mathrm{Se}\right]$ selenite and $\left[{ }^{75} \mathrm{Se}\right]$ selenomethionine in our subjects. However, virtually identical values for absorption of food Se were obtained using the independent results from either tracer study, results which are consistent with the validity of the assumption.

Estimates of the absorption of food Se by man have not previously been made. Our results, which indicate that about 0.8 of food Se is absorbed, confirm the high dietary availability of food Se, at least in New Zealand. Moreover, it is clear that true intestinal absorption of food $\mathrm{Se}$ is materially higher than apparent absorption ([food $\mathrm{Se}-$ faecal $\mathrm{Se}] \div$ food $\mathrm{Se}$ ) which was $0.49-0.60$ (mean 0.55 ) for the four subjects in the intake-output study.

\section{Whole-body Se}

We have attempted to estimate whole-body Se indirectly, (Table 6), using measurements obtained following the administration of ${ }^{75} \mathrm{Se}$ to normal persons. All three methods used depend upon certain assumptions, the validity of which need to be examined.

The most important of these assumptions, which critically affects the validity of all three methods, is that absorbed ${ }^{75} \mathrm{Se}$ is a true tracer for absorbed food Se. In view of the observed differences in occupancy between $\left[{ }^{75} \mathrm{Se}\right]$ selenite and $\left[{ }^{75} \mathrm{Se}\right]$ selenomethionine in our subjects, this assumption is manifestly not true for both radioactive tracers, and it seems likely that it is not strictly true for either. The difference in the metabolism of the two tracers probably accounts for the approximately twofold difference between the estimates of whole-body Se derived using [ ${ }^{75}$ Se]selenomethionine and those obtained using $\left[{ }^{75}\right.$ Se $]$ selenite. It is not possible to be certain which of these tracers is the more nearly valid, but general considerations indicate that $\left.{ }^{75} \mathrm{Se}\right]$ selenomethionine is perhaps the more likely candidate. Food Se was more efficiently absorbed than selenite $\mathrm{Se}$, which would suggest that absorbed food Se is more likely to be biologically similar to selenomethionine Se. Further, it has been shown that selenomethionine is one of the major forms of Se in cereal plants (Peterson \& Butler, 1962; Olson, Novacek, Whitehead \& Palmer, 1970), although there is no evidence for the existence of this selenoamino acid in animal tissues (Jenkins, 1968; Olson \& Palmer, 1976).

A second assumption, which also affects the validity of all three methods of estimating whole-body Se, is that there were no unmeasured losses of ${ }^{75} \mathrm{Se}$. If there were such losses, through skin or in expired air, our estimates of whole-body Se would be too high. We do not 


\section{Table 6. Whole-body Se in New Zealand women (mg)}

\begin{tabular}{|c|c|c|c|c|}
\hline Subject & $\begin{array}{l}\text { From specific activity of } \\
\text { urinary } \operatorname{Se}(\operatorname{method} a)^{*}\end{array}$ & $\begin{array}{l}\text { From whole-body and } \\
\text { plasma occupancy of }{ }^{75} \mathrm{Se} \\
(\text { method } b)^{*}\end{array}$ & $\begin{array}{l}\text { From absorbed food Se and } \\
\text { whole-body occupancy of } \\
{ }^{75} \mathrm{Se}(\operatorname{method} c)^{*}\end{array}$ & Mean \\
\hline \multicolumn{5}{|c|}{ (A) Selenomethionine study } \\
\hline $\begin{array}{l}\mathbf{G} \\
\mathbf{R}\end{array}$ & $\begin{array}{r}5 \cdot 4 \\
10 \cdot 0\end{array}$ & $\begin{array}{l}4 \cdot 3 \\
7 \cdot 2\end{array}$ & $\begin{array}{l}4 \cdot 3 \\
8 \cdot 9\end{array}$ & $\begin{array}{l}4 \cdot 7 \\
8 \cdot 7\end{array}$ \\
\hline $\begin{array}{l}\mathrm{C} \\
\mathrm{T}\end{array}$ & $\begin{array}{l}4 \cdot 7 \\
7 \cdot 5\end{array}$ & $\begin{array}{l}4 \cdot 1 \\
5 \cdot 3\end{array}$ & $\begin{array}{l}5 \cdot 7 \\
5.9\end{array}$ & $\begin{array}{l}4 \cdot 8 \\
6 \cdot 2\end{array}$ \\
\hline Mean & $6 \cdot 9$ & $5 \cdot 2$ & $6 \cdot 2$ & $6 \cdot 1$ \\
\hline \multicolumn{5}{|c|}{ (B) Selenite study } \\
\hline $\begin{array}{l}\mathbf{G} \\
\mathbf{R} \\
\mathbf{W}\end{array}$ & $\begin{array}{l}3 \cdot 4 \\
2 \cdot 7 \\
2 \cdot 7\end{array}$ & $\begin{array}{l}2 \cdot 3 \\
3 \cdot 2 \\
5 \cdot 0\end{array}$ & $\begin{array}{l}3 \cdot 0 \\
2 \cdot 1 \\
2 \cdot 6\end{array}$ & $\begin{array}{l}2 \cdot 9 \\
2 \cdot 7 \\
3 \cdot 4\end{array}$ \\
\hline Mean & 2.9 & 3.5 & $2 \cdot 6$ & 3.0 \\
\hline \multicolumn{5}{|c|}{ * For details, see pp. $49-5 \mathrm{I}$} \\
\hline
\end{tabular}

believe that this occurred to any significant extent (Thomson \& Stewart, I974; Griffiths et al. I976).

A further assumption necessary for the application of method (a), is that urine $\mathrm{Se}$ is derived from the long-term body pool with an insignificant contribution from recently ingested Se. However, following the administration of either $\left[{ }^{75} \mathrm{Se}\right]$ selenomethionine or [ $\left.{ }^{75} \mathrm{Se}\right]$ selenite, $0.06-0.14$ of the dose was excreted in the urine within $14 \mathrm{~d}$ (Thomson \& Stewart, I974; Griffiths et al. 1976) and the correlation between daily food and urine Se in two of our subjects does indicate that a small proportion of Se is excreted at a faster rate than would occur were all absorbed Se directly incorporated into the long-term body pool. This effect would spuriously increase the apparent whole-body Se, and this may explain the slightly higher values obtained by method $(a)$ compared with methods $(b)$ and $(c)$ in the selenomethionine study.

The use of method $(b)$, which employs the occupancy principle for calculating wholebody Se, depends upon the assumption that all Se entering the body pool is at some time resident in the plasma of the systemic circulation (Orr \& Gillespie, 1968). There is no way of determining if this assumption is valid, but it seems likely to be a reasonable approximation. Because of the absence of the appropriate plasma measurements, whole-blood Se was used for these calculations in the selenite study. Whole-blood Se in normal New Zealanders is generally about $I \cdot 2$ times plasma Se (unpublished observations) and this difference probably accounts for the apparently higher values obtained for whole-body Se of subjects $\mathrm{R}$ and $\mathrm{W}$ with method $(b)$ than with methods $(a)$ and $(c)$ in the selenite study.

Method $(c)$ also depends upon the principle of occupancy. It employs the relationship that, in equilibrium, whole-body Se equals the product of the mean body occupancy of Se and the flux of Se into the body (Orr \& Gillespie, 1968; Riviere et al. 1969). This latter parameter is given by absorbed food Se. It was necessary to correct whole-body occupancy of ${ }^{75} \mathrm{Se}$ for the intestinal absorption of the radioactive tracer for this calculation. This correction is also theoretically appropriate for method $(b)$ but unnecessary in that case because the same factor would have been used to adjust both whole-body and plasma occupancy.

There is only one published report giving an estimate of whole-body Se. From their analyses of samples of human tissues obtained at autopsy, Schroeder et al. (1970) calculated a wholebody Se content of 13-20 mg (mean 14.6) for persons living in New England, USA. As both blood Se (Griffiths \& Thomson, 1974) and dietary Se for United States residents are about 
three times those for New Zealanders and as there is no evidence for a mechanism of conserving Se in man, it is likely that the whole-body Se of New Zealanders is about one-third that of United States residents. On this basis, our estimates of 4-IO mg (mean 6.I) for wholebody Se obtained using the selenomethionine results seem fairly reasonable, whereas the values of $2-5 \mathrm{mg}$ (mean $3 \cdot 0$ ) obtained using the selenite results seem a little low.

\section{Se requirements for man}

It has not been established that Se is an essential trace nutrient for man, although this seems likely in view of the large number of animal species which require this element for health (Andrews et al. 1968; Underwood, 1971). Nor is it yet possible to predict the minimum Se dietary requirement for health in man, but the results of the present study of apparently healthy young New Zealanders suggest that a Se intake of $20-30 \mu \mathrm{g} / \mathrm{d}$ is adequate in this respect. We are continuing our investigations of groups of persons in New Zealand who might, for one reason or another, be at a relatively greater risk of suffering from Se deficiency, and in this way we hope to gain a better understanding of man's minimum Se requirements.

We are particularly grateful to Misses Clare Casey, Mary Taylor and Heather Ward for their willing co-operation and assistance as subjects, to Miss Gaylene Friend for technical assistance, to Miss Helen Poh for the analyses of the diets and to Mr G. F. Spears and Miss Alison Robinson for assistance with the mathematical and statistical analyses of the data. This study was supported by the Medical Research Council of New Zealand.

\section{REFERENCES}

Andrews, E. D., Hartley, W. J. \& Grant, A. B. (I968). N.Z. vet. J. I6, 3.

Griffiths, N. M. (I973). Proc. Univ. Otago med. Sch. 5r, 8.

Griffiths, N. M., Stewart, R. D. H. \& Robinson, M. F. (1976). Br. J. Nutr. 35, 373.

Griffiths, N. M. \& Thomson, C. D. (1974). N.Z. med. J. 80, 199.

Hickey, F. (1968). N.Z. Agriculturalist 18 (3), I.

ICRP - International Commission on Radiological Protection, (I966). Report no.9, p. 14. Oxford: Pergamon Press.

ICRP - International Commission on Radiological Protection. (1971), Report no. 17, p. 69. Oxford: Pergamon Press.

Jenkins, K. J. (1968). Can. J. Biochem. Physiol. 46, I417.

Olson, O. E., Novacek, E. J., Whitehead, E. I. \& Palmer, I. S. (1970). Phytochem. 9, I 81.

Olson, O. E. \& Palmer, I. S. (1976). Metabolism 25, 299.

Orr, J. S. \& Gillespie, F. C. (1968). Science, N.Y. 162, 138.

Peterson, P. J. \& Butler, G. W. (1962). Aust. J. biol. Sci. 15, 126.

Richold, M., Robinson, M. F. \& Stewart, R. D. H. (1977). Br. J. Nutr. 38, 19.

Riviere, R., Comar, D., Kellershohn, C., Orr, J. S., Gillespie, F. C. \& Lenihan, J. M. A. (1969). Lancet i, 389.

Robinson, M. F. (1976). J. human Nutr. 30, 79.

Robinson, M. F., McKenzie, J. M., Thomson, C. D. \& van Rij, A. L. (1973). Br. J. Nutr. 30, 195.

Sakurai, H. \& Tsuchiya, K. (1975). Environ. Physiol. Biochem. 5, 107.

Schroeder, H. A., Frost, D. V. \& Balassa, J. J. (1970). J. chron. Dis. 23, 227.

Thompson, J. N., Erdody, P. \& Smith, D. C. (1975). J. Nutr. 105, 274.

Thomson, C. D. (1972). Proc. Univ. Otago med. Sch. 5o, 3 I.

Thomson, C. D., Robinson, B. A., Stewart, R. D. H. \& Robinson, M. F. (1975). Br. J. Nutr. 34, 50I.

Thomson, C. D. \& Stewart, R. D. H. (1973). Br. J. Nutr. 3o, 139.

Thomson, C. D. \& Stewart, R. D. H. (I974). Br. J. Nutr. 32, 47.

Thomson, C. D., Stewart, R. D. H. \& Robinson, M. F. (I975). Br. J. Nutr. 33, 45.

Underwood, E. J. (1971). Trace Elements in Human and Animal Nutrition, 3rd ed. New York: Academic Press. Watkinson, J. H. (1974). N.Z. med. J. 80, 202.

Wells, N. (1967). N.Z. Soil Bureau Atlas, maps 89, 90. Wellington: Government Printer. 